\title{
An Analysis of the Effects of Child-Peer Interaction on Three-Year-Old Children: Focusing on Moderating Effects of Child Gender and Mediating Effects of Teacher-Child Interaction
}

\author{
Mi-So Kim, Young-Sook Suh \\ Department of Child Welfare Studies, Sookmyung Women's University, Seoul, Korea \\ 교수효능감이 유아 또래 상호작용에 미치는 영향 분석: 만 3세 유아의 \\ 성별 조절효과 및 교사-유아 상호작용 매개효과를 중심으로 \\ 김미소, 서영숙 \\ 숙명여자대학교 아동복지학과
}

\begin{abstract}
Objective: The aim of this study was to identify the impact of mediating effect of teacher-child interaction and the moderating effect of child gender on the relationship between teaching efficacy and child-peer interaction.

Methods: The study's data were based on the 4th Panel study on Korean children from Korea Institute of Child Care and Education. Data from 800 3-year-old participants who were enrolled in children's educational institutions were employed to conduct this study. The panel study on Korean children utilized Teacher Self-Efficacy Scales (TSES) as a measure of Teaching Efficacy, Early Childhood Observation Instrument (ECOI) as a measure of Teacher-Child Interaction, and Peen Interactive Peer Play Scale (PIPPS) as a measure of child peer interaction. The data were analyzed by SPSS, version 22.0, to conduct statistics and Pearson product-moment correlation. AMOS 21.0 was utilized to verify the mediating and moderating effects.

Results: Teacher-child interaction had mediating effects on the relationship between teaching efficacy and child-peer interaction. Although there was no direct relationship between teaching efficacy and child-peer interaction, a positive relationship was found between teacher-child interaction. Child gender had moderating effects on this study model. The influence of teaching efficacy and child peer interaction relationship affected more girls than boys, while teacher-child interaction and child-peer interaction relationship affected more boys than girls.

Conclusion: The identified mediating effects further emphasize the significance of teaching efficacy when deciding child-peer interaction. In addition, the identified moderating effects highlight the importance of child gender when approaching teacher-child and child-peer interaction.
\end{abstract}

Keywords: teaching efficacy, teacher-child interaction, child-peer interaction, child gender, mediating effects, moderating effects

Corresponding Author: Mi-So Kim, Department of Child Welfare Studies, Sookmyung Women's University, 66gil 18, Hyochangwanro, Yongsan-gu, Seoul, Korea

E-mail: kmshylove@naver.com
(C)The Korean Association of Child Studies

This is an Open Access article distributed under the terms of the Creative Commons Attribution Non-Commercial License (http:// creativecommons.org/licenses/by-nc/4.0) which permits unrestricted noncommercial use, distribution, and reproduction in any medium, provided the original work is properly cited. 


\section{서론}

여성의 사회진출과 가족 구조의 축소, 보육료 지원 정책의 변 화에 따라 점점 더 많은 유아들이 유아교육기관을 이용한다. 그 과정에서 대다수의 유아들이 이미 유아기에 가족이 아닌 타인과 관계망을 맺고 상호작용하며 다양한 경험을 한다. 유 아의 교육기관에서의 생활에 중요한 영향을 미치는 요인으로 는 교사 및 또래와의 관계관계이다. Vygotsky의 근접발달지대 (Zone of Proximal Development [ZPD])이론은 유아가 성인이나 또래를 통해 발달이 촉진될 수 있음을 시사한다(Y. S. Suh, Suh, $\mathrm{Kim}, \mathrm{Chea}, \& \mathrm{Kim}, 2013)$. 그리고 유아기에 경험한 사회적 관 계는 이후 유아가 형성할 사회적 관계에 대한 기대감의 기초 를 형성하기에 그 상호작용의 질은 매우 중요한 요인이다.

유아교육기관은 동일한 연령의 또래들이 함께 모여 생활 을 영위하는 집단으로 유아들은 그 안에서 또래와 관계 맺고, 상호작용을 통해 다양한 발달적 과업을 이루어낸다. 최근 학 령기 아동들의 또래간 집단 폭력, 왕따 문제 등이 언론에 빈번 히 등장하며 심각한 사회문제로 대두되었다. 이는 또래관계 의 상당한 부적응 정도를 나타내는 현상으로서 또래관계의 중 요성을 보여주는 것으로 여러 연구에서 유아 또래 상호작용의 질이 이후 유아의 사회적.정서적 발달과 적응을 예측하는 중 요한 요인임이 확인된다. 유아는 또래와의 상호작용 과정에 서 사회적 기술을 습득하고 긍정적, 부정적 감정과 관계를 경 험하면서 주변세계를 학습하게 된다(Bagdi \& Vacca, 2005). 상 호작용을 통한 정서조절능력 향상은 또래 리더십 향상과 교 사와의 친밀한 관계에까지 직접적인 영향력을 미친다(Chi \& Jung, 2011; Kang, 2010; J. H. Lee \& Kim, 2012). 이러한 중요성 으로 유아가 교육기관에서 경험하는 상호작용에 관한 연구들 이 다수 이루어졌으나, 대부분 이미 교육기관에서 충분한 시 간을 보낸 4, 5세 유아가 대상이었다. 하지만 입학 시기가 오 래될수록 학습과 사회 정서적 적응력이 높아지기에(Teltsch \& Breznitz, 1998), 사회적 관계를 처음 시작하는 유아의 상호작 용을 살펴볼 필요성이 있다.

우리나라에서 만 3세 연령은 어린이집에서는 영아반에서 유아반으로 전환하는 시기이고 유치원에서는 입학 시작의 연 령으로 집단생활을 처음 경험하는 시기이기도 하다. 가정에서 교육기관으로 사회적 관계가 확장되는 전이기로, 처음 시작 하는 사회적 관계에서 질 높은 상호작용은 부모와 교사 모두 염려하는 부분이다. 만 2세 영아보다는 신체적 움직임이 자유 로워서 자율적으로 행동하지만 아직 충동적이고 본능적인 자 연성이 더 많이 작용하는 연령으로(C. O. Park \& Kim, 1995),
Piaget의 전조작기 단계 중 전개념적 사고단계에 해당한다. 이 시기 유아의 사고는 기호적 인지발달이 주축을 이루기에 놀이 상황에서 서로 일정한 역할을 수행하는 가상놀이를 통해 사회 적 역할과 상호작용을 연습한다. 또한 어휘력 발달로 또래 간 의 상호작용이 늘어나고 이 과정에서 갈등의 발생과 이를 해 결하려는 사회적 문제해결 기술이 나타나는 시기이기도 하다 (Esaa, 2003). 자신의 욕구를 솔직하게 표현하는 측면이 강한 시기(Y. H. Kim \& Cho, 2007)이기에 인지적으로는 아직 자기 중심적인 성향을 유지하고, 정서적으로는 자신의 감정을 강하 게 표출하는 충동적인 특성이 나타난다. 동시에 사회적으로는 또래와 함께 있기를 원하지만 또래와의 관계 형성과 유지 기 술이 부족하여 갈등 상황이 쉽게 일어나고 자주 발생한다(S. J. Lee, 2004). 이처럼 만 3세 유아는 또래 상호작용이 왕성히 일 어나지만 동시에 그 유형이 아직 정형화되어 있지 않은 연령 이기에 만 3 세 유아가 유아교육기관에서 처음 맺는 상호작용 에 주목할 필요가 있다.

유아들이 유아교육기관에서 경험하는 상호작용은 또래관 계에만 국한되지 않는다. 교사는 유아가 가족이 아닌 성인과 관계를 맺는 최초의 존재로 보육의 질에 영향을 주는 중추적 인 자원이자 환경이다(Y. S. Suh \& Suh, 2005). 교사-유아 상호 작용이 유아의 전인적 발달에 영향을 미치는 것은 여러 연구 를 통해 입증되어 왔고, 현장에서도 교사와 질 높은 상호작용 을 보이는 유아들이 또래 관계나 사회적인 유능성이 높은 것 이 관찰된다. 교사-유아 간에 일어나는 상호작용은 유아의 애 착 안정성(Howes, 1997; Pianta \& Steinberg, 1992)과 긍정적 정 서 표현(Hestense, Kontos, \& Bryan, 1993; Y.-H. Kim \& Park, 2014)에 영향을 준다. 또한 유아의 학습과 사회적 적응 등 전 인적 발달에도 연관되어(Howes \& Smith, 1995) 또래와의 사 회적 관계에 영향을 주는 역할(Brich \& Ladd, 1997; Ladd \& Burgess, 2001; Murray \& Murray, 2004; Pianta, 1994)을 하기에 매우 중요한 요인이다. 따라서 유아교사는 유아교육의 질적 향상을 결정하는 가장 중요한 요인이며 유아들과 함께 생활하 며 유아들의 여러 발달에 직접적인 영향을 미치므로 보육환경 을 이루는 요인들 중 가장 중요한 환경이라 할 수 있다.

하지만 유아교사들은 장시간 운영되는 유아교육기관 특성 상 열악한 근무 조건에서 유아들과 관계를 맺고 있다. 연일 미 디어에 보도되는 아동학대 관련 이슈는 유아교사에 대한 사회 적 인식과 업무에 대한 평가 절하로 이어졌다. 유아교사에 대 한 사회적 불신의 목소리가 높아짐에 따라 의무설치된 CCTV 는 교사들의 하루 일과를 빠짐없이 녹화하고 있다. 이는 유아 교육 현장의 교사들에게 큰 부담을 주고 있으며 자칫 교사-유 
아 상호작용을 저하시킬 수 있다. 이러한 상황에서 교사가 유 아와 질 높은 상호작용을 수행하기 위해서는 교수 수행에 영 향을 미치는 다양한 변인에 대한 고려가 필요하다.

교수효능감은 교사 스스로의 행동에 영향을 주어 교육의 질에 직접적인 영향을 미치는 중요한 요인이다. 교수효능감 이 높은 교사는 자신이 학생의 학습에 긍정적인 영향을 줄 수 있는 다양한 특성을 가지고 있다고 믿기에, 함께 학습에 참여 하거나 지도하는 일을 의미 있게 여긴다(Ashton, 1984; Gibson $\&$ Dembo, 1984). 교수 효능감과 교사-유아 관계의 밀접한 관 련성을 실제로 입증한 연구들(Cheon \& Cho, 2011; Hamre, Pianta \& Downer, 2008; R.-H. Kwon \& Lee, 2015; Mashburn, Hamre, Downer, \& Pianta, 2006; Paik \& Kang, 2014; Shin \& Rhee, 2005)은 교수 효능감은 교수 과제를 수행하는 교사의 개 인적 신념이지만 이러한 신념이 인간관계, 특히 유아와 사회 적 관계의 질을 결정하는 중요한 변인이 될 수 있음을 지적한 다. 따라서 교수효능감은 최근처럼 유아교사와 그들의 교수에 대한 사회적 인식이 부정적인 상황에서 자칫 낮아질 수 있는 교사-유아 상호작용에 영향을 줄 수 있는 변인이 될 수 있다.

그럼에도 아직까지 교수효능감과 교사-유아 상호작용, 유 아 또래상호작용의 관계를 분석한 연구는 미비하다. 또한 유 아가 교육기관에서 경험하는 상호작용에 관한 연구들은 대부 분 이미 교육기관에서 충분한 시간을 보낸 4,5 세를 중심으로 이루어져왔다. 교수효능감과 교사-유아 상호작용, 그리고 유 아 또래 상호작용과 관련된 연구들을 통해 교수 효능감은 교 사-유아 상호작용에 영향을 미치고, 교사-유아 상호작용은 유 아 또래 상호작용에 영향을 미친다는 것을 알 수 있다. 이러한 관계에서 교사-유아 상호작용이 교수 효능감과 유아 또래 상 호작용 두 변인 관계를 매개할 것으로 예측해 볼 수 있다. 그 러나 $\mathrm{Na}$ (2007)은 유아교사의 자기효능감이 유아의 사회적 적 응에 영향을 미치지 않는다고 보고했으며, 교수효능감과 교 사-유아 상호작용, 유아 또래 상호작용의 관계를 본 연구(Y. K. Moon \& Choi, 2015; Sim \& Lim 2017)는 교사-유아 상호작용 의 매개효과를 검증하였으나 이 또한 만 4세 유아가 대상이었 으며 개인 기질에 따른 차이가 없음을 보고하였다.

한편, 지금까지의 유아의 상호작용에 관한 연구들은 유아 를 둘러싼 주변 환경의 중요성을 밝히고 있는데 유아 개인의 내적 요인도 함께 고려해보아야 할 것이다(Y.-H. Kwon, 2012). 교사-유아의 관계 또한 유아와 교사, 그리고 이들을 둘러싼 환 경 요인에 의해 영향을 받는 역동적 특성을 지니는데 여기에 서도 유아의 성별은 그 관계에 영향을 주는 중요한 변인으로 제시되고 있다.
Baker (2006)는 교사-유아 상호작용의 질이 유아의 학습이 나 학교에서의 품행에 영향을 주는데 이 때 성별에 따른 차이 가 있음을 보고하였다. 성별에 따른 유아-교사 관계를 관찰한 연구들은 일반적으로 여아가 남아에 비해 친밀한 교사-유아 관계를 맺고 있으며, 남아가 여아에 비해 교사와 갈등이 높다 고 보고한다(Ann, 2002; Brich \& Ladd, 1997; H. J. Kim \& Jean, 2010; K.-S. Kim \& Kim, 2011). 이는 또래놀이에 있어서도 유 사한 성별에 따른 차이를 보였다(Y.-H. Kim \& Park, 2014; J. Y. Park, Kang, \& Kwon, 2010). 그리고 이러한 유아의 성별에 따른 차이는 유아기부터 초등학교 시기까지 지속되는 특성으로 알 려져 있다. 아직 성징이 나타나지 않은 유아기에도 놀이나 상 호작용에서 차이를 보고하는 연구들은 유아교육실천 현장에 서 유아의 성별을 고려한 관점의 필요성을 시사한다. 하지만 성별에 따른 차이를 보고하는 다수의 연구와 달리 일부 연구 에서는 교사-유아 관계에서 유아 성별에 따른 유의미한 차이 가 나타나지 않았으며(Y.-H. Kwon, 2012; E.-S. Moon \& Kim, 2011; Park, 2013), 교사에 대한 유아의 의존성도 성별에 따른 차이가 없는 것으로 나타났다(Birch \& Ladd, 1997; E.-S. Moon \& Kim, 2011; Park, 2013).

최근 성차에 대한 갈등이 고조되는 사회의 모습(Heo, 2017) 은 유아교육현장의 교사에게 성별과 성 가치관에 대해 어떤 접근을 해야 하는지에 대해 고민하게 만든다. 하지만 성 가치 관과 달리 성별은 유아가 선택하거나 바꿀 수 없는 생물학적 요인이다. 만약 본 연구에서 교사-유아 관계와 유아 또래 관계 에서 유아의 성차가 확인될 경우, 유아 개인을 더욱 배려한 상 호작용이 가능해질 것이다. 일률적인 상호작용은 개인에 대한 배려를 할 수 없으며, 현상 자체에 대한 인정과 이해가 그 해결 점이 될 것이다(Heo, 2017). 교사-유아 관계와 유아 또래 관계 에 유아의 성차가 존재한다면 남아와 유아의 성별에 따른 차 이를 개인차로 인식하고, 각 관계에서 유아의 성별에 따른 차 이에 대해 이해를 통해 유아의 개별성을 지켜줄 수 있게 된다.

유아교육현장에서 교사와 유아의 관계, 유아와 또래와의 관계는 분리될 수 없다. 따라서 교사와 유아의 관계, 유아의 또 래 관계는 함께 다루어져야한다. 하지만 아직까지 유아교육 기관 적응력이 높지 않은(Teltsch \& Breznitz, 1998) 만 3세 유아 를 대상으로 살펴본 연구는 미비하며, 교사의 개인 변인인 교 수효능감과 유아의 개인 변인인 성별의 관계를 함께 구조적으 로 분석한 연구가 부족한 상황이다. 가르침과 돌봄이 분리될 수 없는 유아교육 실천 현장(Yeom, 2005)에서 교사와 유아의 상호작용은 필수적으로 일어난다. 본 연구 결과에서 유아교사 의 교사-유아 상호작용의 매개효과가 확인된다면, 교사-유아 
상호작용이 유아교사의 개인적 특성인 교수효능감이 유아의 또래 관계에까지 영향을 미치게 만드는 변인임을 증명하며 그 중요성을 제고할 수 있다. 또한 유아 성별의 조절 효과가 확인 될 경우 유아교육 현장에서 유아의 성별을 고려한 실천의 필 요성을 제시할 수 있다. 이를 검증하기 위해 다음과 같은 연구 문제를 설정하였다.

\section{연구문제 1}

유아교사의 교수 효능감과 유아 또래 상호작용, 교사-유아 상 호작용은 어떠한 관계를 가지고 있는가?

\section{연구문제 2}

유아교사의 교수효능감과 교사-유아 상호작용, 유아 또래 상 호작용의 관계는 유아의 성별에 따라 차이가 있는가?

\section{연구방법}

\section{연구대상}

본 연구는 육아정책연구소에서 수행하고 있는 종단연구인 한 국아동패널조사(Panel Study on Korean Children [PSKC]) 데 이터 중 4차년도 자료를 사용하였다. 연구대상의 인구사회학 적 특성은 다음과 같다. 연구대상 유아의 성별은 남아 404 명 (50.5\%), 여아 396명(49.5\%)로 남아와 여아의 비율이 거의 비 슷하였으며 유아의 평균월령은 38개월로 39개월 이상이 337 명 $57.8 \%), 38$ 개월 이하가 463 명(42.2\%)로 가장 낮은 월령은 35 개월, 가장 높은 월령은 42 개월이다. 조사대상 부모 중 어머 니가 778명(97.2\%), 기타 22명(2.8\%)으로 어머니 응답이 대부 분이었으며, 어머니 취업여부는 취업모가 383 명(47.8\%), 비 취업모가 417 명 $(52.2 \%)$ 을 나타났다. 아버지의 최종학력은 고 졸 이하가 212 명 $(26.5 \%)$, 전문대졸이 180 명 $(22.5 \%)$, 대졸 이 상이 402 명 $(50.2 \%)$ 이었고, 어머니의 최종학력은 고졸이하 가 241 명(30.1\%), 전문대졸이 220 명 $(27.5 \%)$, 대졸 이상이 338 명(42.2\%)을 차지하였다. 유아가 다니는 유아지원기관은 어 린이집 이용이 770 명 $(96.3 \%)$, 유치원 16 명(2\%), 기타 14 명 $(1.7 \%)$ 로 대부분이 어린이집을 이용하는 것으로 나타났다. 어 린이집의 유형은 민간과 가정이 601명(75.1\%), 국공립과 법 인이 142 명(17.7\%), 기타 부모협동이나 학원, 유치원등이 36 명 $(4.5 \%)$, 직장이 21 명 $(2.6 \%)$ 순으로 나타나 민간, 가정어린 이집의 이용이 가장 높았다. 유아 담임교사의 최종 학력은 고
졸 106명(13.2\%), 전문대졸 458명(57.3\%), 대졸 이상이 236명 (29.5\%)으로 전문대졸이 가장 많았다. 담임교사의 총 경력은 초임교사부터 최고 271 개월까지 평균 59개월로 3년 미만이 329 명(41.1\%), 3년 이상 6년 미만이 200명(25\%), 6년 이상 271 명(33.9\%)을 차지하였다.

\section{연구도구}

본 연구에서 사용한 척도들의 구성은 한국아동패널 자료에서 문항내용을 참고하였고 연구에 사용된 척도들은 다음과 같다.

$$
\text { 교수효능감 }
$$

한국아동패널의 '교수효능감' 척도는 Bandura (2006)의 교사 자기 효능감 TSES (Teacher Self-efficacy Scale)를 토대로 Y. H. $\operatorname{Kim}$ 과 $\operatorname{Kim}$ (2008)이 요인구조를 분석한 문항에서 한국아동패 널 연구진이 일부 수정한 척도로 사용하였다. Bandura (2006) 의 교사 자기 효능감 척도 TSES (Teacher Self-efficacy Scale)는 상황특정적인 척도로 다양한 교육적 상황에 대처하는 교사로 서의 능력을 측정할 수 있다는 장점이 있다. 기존 Y. H. Kim과 $\operatorname{Kim}$ (2008)의 척도는 가정연계 및 긍정적 학습 환경 조성 효능 감, 교수 효능감, 지역기관 연계 효능감, 의사결정 참여 효능감 의 4 가지 요인으로 구분되었지만 한국아동패널에서는 교수효 능감을 특정 하는 7문항을 사용하였다. 4차년도 '기관대상 질 문지'의 8번에 기재되어 있으며, 응답방식은 전혀 그렇지 않다 (1점)부터 매우 그렇다(5점)의 Likert식 5점 척도로 평정하도록 되어있으며, 가능한 점수 범위는 총 7점부터 35점으로 점수가 높을수록 교수효능감이 높음을 의미한다. 교수효능감의 정도 는 교사 대상 질문지를 통해 조사가 이루어졌으며, 모든 교사 에게 동일한 문항을 적용하였다. 교수효능감 관련 문항은 교 수 활동에 관련된 내용으로 구성되어 있어 요인분석 결과 1 개 의 요인으로 하위 요인들이 나누어지지 않았다. 따라서 문항 순으로 3집단으로 나누어 하위 요인을 구성하였고 신뢰도는 Cronbach's $\alpha$ 값 .86으로 나타났다.

\section{유아 또래 상호작용}

한국아동패널의 '유아 또래상호작용' 척도는 Fantuzzo, SuttonSmith, Coolahan, Manz, Cannig, \& Debnam (1995)의 아동 또래 놀이행동 척도 PIPPS (Peen Interactive Peer Play Scale)와 Choi와 Shin (2011)의 PIPPS의 국내적용 타당화 연구의 문항을 토대 
로 한국아동패널 연구진이 재구성하여 사용하였다. 이 도구는 4 차년도 '기관대상 질문지'의 25 번에 기재되어 있으며, 놀이상 호작용 9문항, 놀이방해 13 문항, 놀이단절 8 문항으로 구성된 총 30문항 교사보고식 척도이다. 응답방식은 전혀 그렇지 않 다(1점)부터 매우 그렇다(4점)의 Likert식 4점 척도로 평정하고 있다. 요인분석 결과 6 개의 요인으로 나왔지만 6 개 요인이 명 확히 구분되지 않았기에 잠재변인에 대한 탐색적 요인분석을 실시하였다. 주성분분석을 사용하였으며 한국아동패널에서 사용한 설문 도구가 3 개 하위 영역으로 되어있기에 3 개 요인 추출로 고정하여 베리맥스 회전방식을 사용하였다. 탐색적 요 인분석 결과 질문지 문항에 해당되는 하위요인들로 묶였고 다 른 요인으로 섞인 문항들(15번 문항, 36번 문항)도 하위영역별 로 한 개 씩 있었으나 매우 근소한 차이였기에 패널에서 사용 한 하위요인대로 분류하였다. 요인부하량대로 3집단으로 구 성되었으며, 신뢰도는 Cronbach's $\alpha$ 값 .87로 나타났다.

$$
\text { 교사-유아 상호작용 }
$$

한국아동패널의 '교사-유아 상호작용' 척도는 Holloway \& Reichhart-Erickson (1988)의 ECOI (Early Childhood Observation Instrument)를 M. J. Kim (1991)가 번역한 것을 토대로 한국아 동패널 연구진이 일부 수정하여 사용하였다. 이 척도는 4차년 도 '기관대상 질문지'의 9번에 기재되어 있으며, 보육교사가 유아와 얼마나 온정적, 반응적이며 긍정적으로 상호작용하는 지를 측정하기 위한 총 10 문항의 자기보고식 척도이다. 응답 방식은 전혀 그렇지 않다(1점)부터 매우 그렇다(5점)의 Likert 식 5점 척도로 평정하고 있다. 가능한 점수 범위는 총 10점부 터 50점으로 점수가 높을수록 보육교사와 유아의 상호작용의 질이 높음을 의미한다. 요인분석 결과 1 개의 요인으로 하위 요 인들이 나누어지지 않아 문항 순으로 3집단으로 하위 요인을 구성하였고 신뢰도는 Cronbach's $\alpha$ 값이 .90으로 나타났다.

\section{자료분석}

본 연구에서는 교수 효능감과 교사-유아 상호작용, 유아 또 래 상호작용 및 유아 성별의 구조적 관계를 알아보고자 한 다. 자료는 SPSS 22.0 (IBM Co., Armonk, NY)과 AMOS 21.0 (IBM Co., Armonk, NY) 프로그램을 사용하여 분석하였다. 연 구대상의 사회인구학적 특성을 살펴보기 위해 빈도와 백분율 을 산출하였고, 측정도구의 타당도와 신뢰도를 검증하기 위 해 Cronbach's $\alpha$ 값을 산출하였다. 자료의 정규분포를 측정변
인의 왜도, 첨도를 확인하여 검증하고, 측정변인들 간의 상관 관계를 분석하여 다중공선성 및 각 변인들 간의 관계를 알아 보았다. 교수효능감이 교사-유아 상호작용을 통해 유아또래 상호작용에 미치는 경로를 살펴보기 위하여 구조방정식모형 (Structural Equation Modeling [SEM]) 분석을 실시하였다. 측정 변인들이 잠재변인을 잘 설명하는지 알아보기 위해 확인적 요 인분석을 실시한 뒤, 적합도 분석을 통해 본 연구에 사용가능 한 모형인지 검증하였다. 다음으로 본 연구에서 설정한 구조 모형의 타당도를 검증하기 위해 경로계수의 유의성을 검토하 여 잠재변인과의 관계를 분석하여 매개효과를 확인하였다. 변 인들 간의 영향력을 분명하게 알 수 있도록 직접효과, 간접효 과를 분석하고 Bootstrapping과 Sobel test를 사용하여 매개효과 를 검증하였다. 마지막으로 다집단 분석을 통해 검증된 모형 에 유아의 성별 변인이 조절효과를 갖는지 확인하였다.

\section{연구결과}

\section{유아교사의 교수 효능감과 유아 또래 상호작 용, 교사-유아 상호작용의 관계}

유아교사의 교수 효능감과 유아 또래 상호작용, 교사-유아 상 호작용의 직·간접적인 관계를 파악하기 위해 구조모형분석 이 필요했다. 기술통계와 상관관계 분석을 통해 자료의 정규 분포와 변인간 상관을 확인하였고, 본 연구에서 설정한 모형 이 측정 변인을 적절히 설명할 수 있는지 확인적 요인분석과 타당도 검증을 실시하였다. 이후 구조모형분석을 통해 유아교 사의 교수 효능감과 유아 또래 상호작용, 교사-유아 상호작용 의 관계를 파악하였다.

\section{기술통계 및 상관관계 분석}

자료의 정규분포 여부를 점검해보기 위해 평균과 표준편차, 왜도, 첨도를 검토했다. 교수효능감과 교사-유아상호작용, 유 아또래상호작용은 각각 7 개, 10 개, 30 개 문항으로 측정되었는 데, 문항수가 많음으로써 잠재변인의 분산이 커질 수 있기 때 문에, 각 잠재변인을 구성하는 항목들의 문항꾸러미(parcel) 를 구성하였고 각 잠재변인 별로 3 개의 문항꾸러미로 측정변 인을 구성하였다. 측정 변인의 평균은 $2.84 \sim 4.24$, 표준편차는 .41 .61, 왜도는 -.76에서 .05사이였고, 첨도는 -.78에서 1.66 사이로 나타났다. 정규분포 요건을 갖추기 위한 왜도와 첨도 
Table 1

Correlation Coefficients Among Variables

\begin{tabular}{|c|c|c|c|c|c|c|c|c|c|}
\hline & 1 & 2 & 3 & 4 & 5 & 6 & 7 & 8 & 9 \\
\hline 1. Teaching efficacy 1 & 1 & & & & & & & & \\
\hline 2. Teaching efficacy 2 & $.57^{* *}$ & 1 & & & & & & & \\
\hline 4. Teacher-child interaction 1 & $.46^{* *}$ & $.48^{* *}$ & $.55^{* *}$ & 1 & & & & & \\
\hline 5. Teacher-child interaction 2 & $.48^{* *}$ & $.48^{* *}$ & $.59^{* *}$ & $.70^{* *}$ & 1 & & & & \\
\hline 7. Child peer interaction 1 & $.14^{* *}$ & $.14^{* *}$ & $.15^{* *}$ & $.15^{* *}$ & $.19^{* *}$ & $.22^{* *}$ & 1 & & \\
\hline 8. Child peer interaction 2 & $.17^{* *}$ & $.19^{* *}$ & $.21^{* *}$ & $.16^{* *}$ & $.20^{* *}$ & $.19^{* *}$ & $.47^{* *}$ & 1 & \\
\hline 9. Child peer interaction 3 & $.13^{* *}$ & $.11^{* *}$ & $.13^{* *}$ & $.11^{* *}$ & $.15^{* *}$ & $.15^{* *}$ & $.44^{* *}$ & $.26^{* *}$ & 1 \\
\hline
\end{tabular}

Table 2

Model Fit of the Measurement Model

\begin{tabular}{ccccc}
\hline RMSEA & GFI & NFI & TLI & CFI \\
\hline .027 & .990 & .988 & .993 & .996 \\
\hline
\end{tabular}

의 절대값이 2.0 이하로 나와 구조방정식의 기본 가정인 다변 량 정규분포를 이루고 있음을 확인하였다.

주요 변인들 간의 관련성을 파악해보기 위해 Pearson 적률 상관계수를 산출하여 상관관계를 살펴보았으며 결과는 Table 1 과 같다. 모든 변인들 간의 상관관계가 0.01 수준에서 유의한 것으로 나타났으며 변인들 간의 상관관계가 유의미하기에 변 인간 경로 설정이 가능하였다. 상관분석 결과 .65 .72의 다소 높은 상관관계가 확인되어 이들 변인의 다중공선성 진단을 실 시하였고 분산팽창계수(Variance Inflation Factor [VIF])를 살펴 본 결과, VIF 지수는 $1.818 \sim 2.287$ 로 나타나 다중공선성의 문 제는 없다고 판단했다. 그 외 모든 변인들 간에는 지나치게 높 은 상관이 없어 측정 변인간 상관은 적절함을 확인할 수 있다.

\section{측정모형분석}

측정모형의 적합도를 평가하기 위해 확인적 요인분석 (Confirmatory Factor Analysis [CFA])을 실시하였다. 본 연구 측 정모형의 적합도 지수는 Table 2에 제시한 것과 같이 RMSEA 는 $.027, \mathrm{GFI}$ 는 $.990, \mathrm{NFI}$ 는 $.988, \mathrm{TLI}$ 는 $.993, \mathrm{CFI}$ 는 .996로 매 우 좋은 적합도를 보이고 있었다. 잠재변인들 간의 상호 상관 을 살펴본 결과 측정변인의 요인부하량은 모든 측정변인들이 절대값 .50 이상, C.R. (Critical Ratio)의 값이 모두 $p<.001$ 수 준에서 유의한 것으로 나타났다. 따라서 본 연구에서 설정한 측정모형은 표본 자료를 적정하게 설명할 수 있도록 설계된
모형임이 인정되었다는 것으로 확인할 수 있다.

측정모형분석을 실시하여 수용 가능한 적합도 확인 후, 타 당도를 평가해보았다. 측정모형의 타당성을 평가하기 위해서 는 집중타당성과 판별타당성을 검증해야한다. 본 연구에서는 집중타당성은 개념신뢰도(Construct Reliability [CR]) 방법을, 판별타당성은 평균분산추출(Average Variance Extracted [AVE]) 방법을 사용하였다. 개념신뢰도 계산 결과 교사-유아 상호작 용은 0.961, 교수효능감은 0.941 , 유아또래상호작용은 0.913 으 로 나타나 모든 변수의 집중타당성이 확인되었다. 평균분산추 출 계산 결과 교사-유아 상호작용은 .892, 교수효능감은 .844, 유아또래상호작용은 .785로 나타나, 모든 변수의 AVE 값이 가 장 큰 상관계수의 제곱값인 .582보다 크기에 판별타당성을 확 인하였다.

\section{구조모형분석}

구조모형의 적합도를 평가하기 위해 유아교사의 교사-유아 상호작용이 교수효능감과 유아 또래 상호작용의 관계를 매 개하여 직·간접적으로 영향을 미치는 모형을 만들어 적합도 를 평가하였다. 독립변수인 교수효능감의 경우 유아교사의 경 력이 영향을 주었다는 연구들이 일부 있었기에(H. J. Kim \& Cho, 2009; C. H. Park \& Na, 2012), 유아교사의 총경력을 통 제 변인으로 설정하여 적합도를 Table 3에 제시하였다. 구조모 형의 적합도 지수는 RMSEA는 .027, GFI는 .988, NFI는 .985, 
Table 3

Model Fit of the Alternative Model

\begin{tabular}{ccccc}
\hline RMSEA & GFI & NFI & TLI & CFI \\
\hline .027 & .988 & .985 & .991 & .994 \\
\hline
\end{tabular}

Table 4

Path Estimates of the Latent Variables

\begin{tabular}{lcccc}
\hline & $B$ & $\beta$ & $S E$ & $p$ \\
\hline Teaching efficacy $\rightarrow$ Child-peer interaction & .068 & .089 & .060 & .167 \\
Teaching efficacy $\rightarrow$ Teacher-child interaction & .705 & .779 & .041 & $* * *$ \\
Teacher-child interaction $\rightarrow$ Child-peer interaction & .194 & .233 & .065 & $* *$ \\
\hline
\end{tabular}

${ }^{* * *} p<.001 .{ }^{* *} p<.01$

Figure 1. Final structural model.

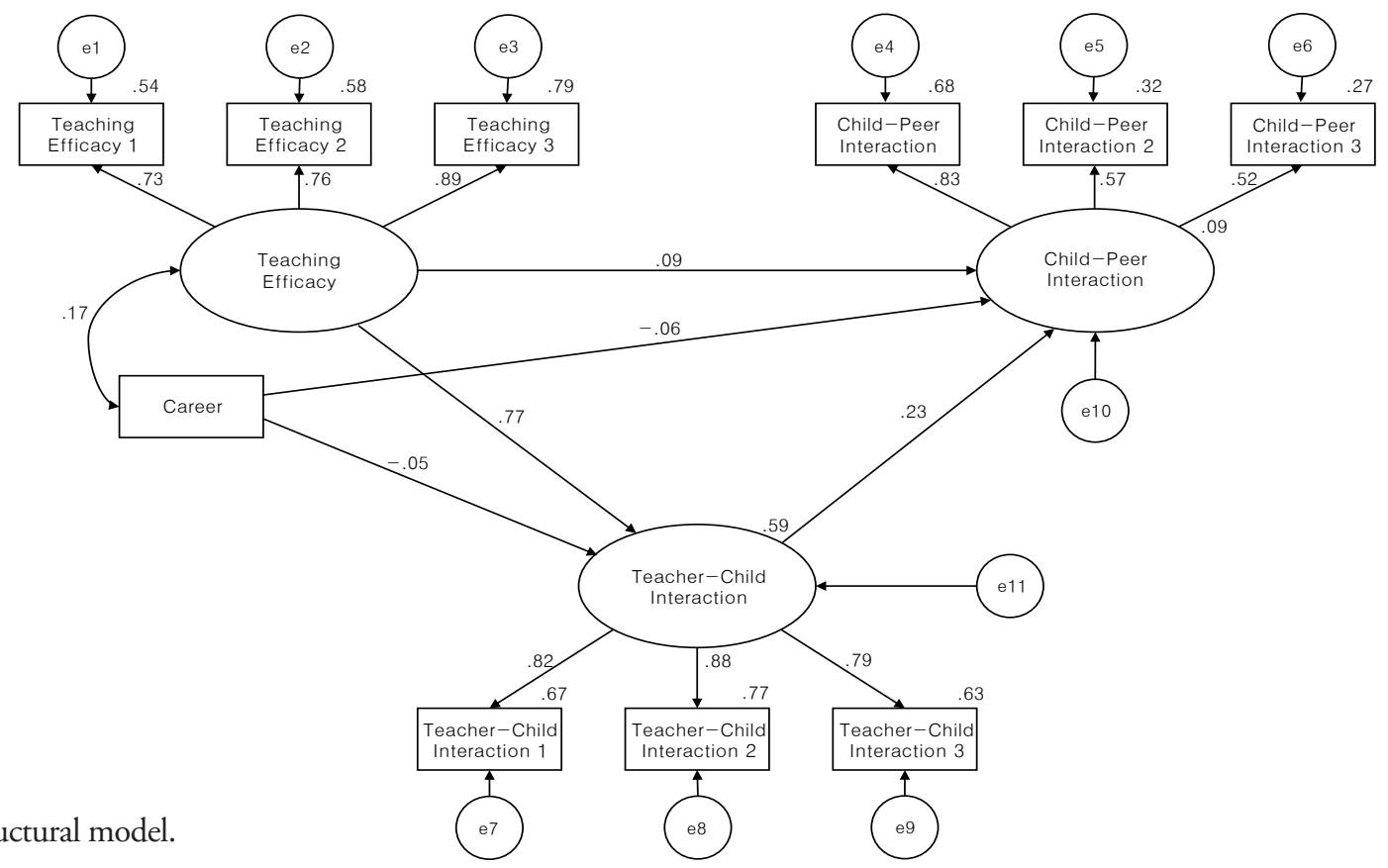

Table 5

Direct, Indirect, and Total Effects of the Model

\begin{tabular}{lccc}
\hline & Direct & Indirect & Total \\
\hline Teaching efficacy $\rightarrow$ Child-peer iteraction & .089 & $.180^{* *}$ & $.269^{* *}$ \\
Teaching efficacy $\rightarrow$ Teacher-child interaction & $.773^{* * *}$ & - & $.773^{* * *}$ \\
Teacher-child interaction $\rightarrow$ Child-peer interaction & $.233^{* *}$ & - & $.233^{* *}$ \\
\hline
\end{tabular}

Note. $N=800$.

${ }^{* * *} p<.001 .{ }^{* *} p<.01$.

Table 6

Sobel Test

\begin{tabular}{ccc}
\hline Path & Indirect & $z$ \\
\hline Teaching efficacy $\rightarrow$ Teacher-child interaction $\rightarrow$ Child-peer interaction & .180 & $.2 .94^{* * *}$ \\
\hline
\end{tabular}

Note. $N=800$.

${ }^{* * *} p<.001 .{ }^{* *} p<.01$. 
Table 7

Structural Model Invariance Across the Groups

\begin{tabular}{|c|c|c|c|c|c|}
\hline \multirow[b]{2}{*}{ Path } & \multicolumn{2}{|c|}{ Unconstrained model } & \multicolumn{2}{|c|}{ Constrained model } & \multirow[b]{2}{*}{ C.R } \\
\hline & boys & girls & boys & girls & \\
\hline Teaching efficacy $\rightarrow$ Child-peer interaction & -.012 & $.297^{*}$ & $.088^{*}$ & $.081^{*}$ & $1.961^{*}$ \\
\hline Teacher-child interaction $\rightarrow$ Child-peer interaction & $.422^{* * *}$ & -.063 & $.262^{* *}$ & $.212^{* *}$ & $-2.969^{* *}$ \\
\hline
\end{tabular}

${ }^{* * *} p<.001 .{ }^{* *} p<.01$.

TLI는 .991, CFI는 .994로 매우 좋은 적합도를 보이고 있었다.

유아교사의 교사-유아 상호작용이 교수효능감과 유아 또 래 상호작용의 관계를 매개한다는 가설을 검증하기 위해 연구 문제에 따라 설정된 구조모형을 분석하였다. 구조모형에서 교 사-유아 상호작용과 교수효능감은 유아 또래 상호작용을 약 $58.6 \%$ 설명하는 것으로 나타났고 $\left(R^{2}=.586\right)$, 구조모형 분석결 과는 Table 4 와 Figure 1에 제시하였다. 구조모형 분석 결과 유 아교사의 교수효능감은 교사-유아 상호작용에 미치는 영향은 정적으로 유의하였으며 $(\beta=.779, p<.001)$, 교사-유아 상호작 용이 유아 또래 상호작용에 미치는 영향도 정적으로 유의하였 다 $(\beta=.233, p<.01)$. 유아교사의 교수효능감은 유아 또래 상 호작용에 대한 전체효과 $(\beta=.269, p<.01)$ 중에서 간접효과 $(\beta$ $=.180, p<.01)$ 만 있는 것으로 나타나 유아교사의 교사-유아 상호작용은 교수효능감과 유아 또래 상호작용의 관계에서 완 전 매개의 역할을 한다는 것을 알 수 있었다.

경로모형에서 간접효과를 통계적으로 검증하기 위하여 Bootstrapping과 Sobel test를 실시하였고 그 결과를 Table 6에 제 시하였다. Bootstrapping 결과 간접효과의 유의수준이 0.01로 0.05 보다 작아 통계적으로 유의미함을 검증하였으며, Sobel test 결과 검증치 $z$ 값이 2.94 ( $p$ <.001)로 나타나 두 검증 모두 유의미 하게 나왔다는 점에서 매개효과가 유의미함을 확인할 수 있다.

\section{유아 성별의 조절효과분석}

지금까지 유아교사의 교사-유아 상호작용이 교수효능감과 유 아 또래 상호작용의 관계에서 매개 역할을 한다는 것이 검증 되었기에 본 연구모형에서 유아의 사회인구학적 요인인 성 별에 따라 어떠한 차이가 존재하는지 검증하기 위해 구조방 정식을 이용한 집단 간 비교 분석(test of the structural model invariance across the groups)과 집단 간 C.R (Critical Ratio for differences between parameters)값 비교를 통한 모수 차이 검증 을 실시하였다. 결과는 Table 7에 제시하였다.

형태동일성은 기존 모형에서 만족하였으므로 측정동일성
제약을 검정한 후 집단 간 비교를 통해 자녀의 성별 차이가 조 절효과를 갖는지 확인했다. 남아 $(N=404)$ 와 여아 $(N=396)$ 두 집단에서 요인적재치를 동일하게 고정하고 측정동일성 검증 을 실시한 결과 RMSEA는 .027, GFI는 .990, NFI는 .988, TLI 는 .986, CFI는 .991로 모형의 적합도가 높게 나타나 집단 간에 교차타당성이 존재한다고 보았다. 경로계수에 대해 등가제약 을 가해 제약모델을 설정하고 분석한 결과 동일성 제약을 가 한 모델도 비제약모델처럼 모델의 적합도(RMSEA $=.033$, TLI $=.980, \mathrm{CFI}=.991)$ 가 높게 나타나 모형의 안정성을 검증할 수 있었다. 측정모형인 비제약모델과 제약모델의 모든 경로의 표 준화된 계수와 유의성을 비교해 조절효과를 검증하였다. 검증 결과 교수효능감이 유아 또래 상호작용에 미치는 영향력은 비 제약모델에서는 여아의 경우에만 유의하게 나타났다. 교사유아 상호작용이 유아 또래 상호작용에 미치는 영향력이 비제 약모델에서는 남아의 경우에만 유의하게 나타났다. 대응별 모 수 차이 검증을 통해 유아 성별의 조절효과를 재확인해본 결 과, 유아교사의 교수 효능감이 유아 또래 상호작용에 미치는 경로와 교사-유아 상호작용이 유아 또래 상호작용에 미치는 경로의 C.R값이 각각 $1.961(p<.05)$ 과 -2.969 ( $p<.01)$ 로 산 출되었다. 이는 교수효능감이 유아 또래 상호작용에 미치는 경로와 교사 유아 상호작용이 유아 또래 상호작용에 미치는 경로에 유아 성별의 차이가 있음을 검증한 것으로 집단 간 차 이 비교와 동일한 결과이다. 구조방정식에서 조절효과를 검증 하는 두 분석 방법을 통해 유아교사의 교수효능감이 유아 또 래 상호작용에 미치는 영향력과 교사-유아 상호작용이 유아 또래 상호작용에 미치는 영향력에 유아 성별에 따른 차이가 있음을 확인하였다.

\section{논의 및 결론}

본 연구는 만 3 세 유아 성별에 따른 또래 상호작용과 교사-유아 상호작용, 교수효능감의 관계를 구조적으로 분석하기 위한 목 
적으로 실시되었다. 이러한 목적을 달성하기 위하여 육아정책 연구소에서 제공하는 한국아동패널 제 4 차 자료 1,754 명 중 유 아교육기관을 다니고 있는 만 3세 유아 800명을 대상으로 검증 하였다. 본 연구에서 나타난 주요 결과와 논의는 다음과 같다.

첫째, 유아교사의 교사-유아 상호작용은 교수효능감과 유 아 또래 상호작용의 관계를 매개한다. 이는 교수효능감이 높 을 경우 교사-유아 상호작용이 높아지며, 교사-유아 상호작용 이 높아짐으로써 유아 또래 상호작용도 높아지는 것을 의미한 다. 그리고 교수효능감은 유아또래상호작용에 직접적인 영향 을 미치지 못하여 교사-유아상호작용이 교사 개인변인인 교 수효능감과 유아 또래 상호작용을 연결하는 완전매개 역할 을 함을 알 수 있다. 이는 유아 또래 상호작용 제고를 위해 교 사-유아 상호작용이 중요한 변인임이 증명되며, 선행연구와 도 일치한 결과이다(Brich \& Ladd, 1997; Ladd \& Burgess, 2001; Murray \& Murray, 2004; Pianta, 1994). 양질의 교사-유아 상호 작용은 유아가 또래 관계에서 다양한 경험과 모델링을 통해 긍정적 사회화 과정을 이루어낸다. 그리고 유아교육 현장에서 이를 실천시키기 위해서는 양적인 부분보다 질적인 부분에 더 초점을 맞춰야 할 것이다.

OECD (Organization for Economic Cooperation and Development, 2012)는 유아교육의 질 향상을 위해 집단 내 아 동 수와 교사 대 아동 비율을 낮출 것을 권고한다. 교사 대 아 동의 비율이 낮을수록 양질의 교사-유아 상호작용이 이루어 지기 때문이다. 일반적으로 교사 대 유아의 비율이나 집단의 크기, 교사의 경력 등은 유아교육기관의 질을 향상시키기 위 한 구조적 질에 포함되는 변인들이다. 과정적 질은 교사-유아 상호작용, 교사의 행동, 온정적이고 민감한 보육 유아에게 제 공되는 교육의 질과 직접적인 연관이 있는 것을 의미한다. 결 국 구조적 질과 과정적 질이 어떻게 이루어지느냐에 따라 유 아교육현장의 질의 높고 낮음이 결정된다. 아직까지 교사 대 아동 비율이 높은 대한민국 교육 현장에서, 양질의 보육을 확 보하기 위해서는 교사-유아 상호작용의 질 향상이 필수적이 다. 또한 정량적으로 평가하여 등급을 선정하는 도구가 아닌 CLASS (Classroom Assessment Scoring System)와 같은 상호작용 중심의 질 평가 척도를 통한 평정과 교사 컨설팅이 필요할 것 이다. 더불어 교사-유아 상호작용에 영향을 미치는 유아교사 의 교수효능감이 높아질 수 있는 교육실천현장을 위한 정책 적, 학문적 접근이 필요하다. 최근 평가인증 통합지표에 새로 이 등장한 교사의 업무 스트레스 관련 지표나 2018년 7월부터 시행되는 보육교사 휴게시간은 교수효능감과 교사-유아 상호 작용의 질에 영향을 줄 수 있는 새로운 접근일 것이다.
둘째, 유아의 성별에 따라 교수효능감과 교사-유아 상호작 용에 영향을 받는 유아 또래 상호작용 수준에 차이가 있다는 것을 알 수 있다. 교사-유아 관계에서의 성차, 혹은 유아 또래 관계에서의 성차로 분석한 기존 연구들과 달리, 본 연구는 유 아를 둘러싼 교사와 또래관계를 함께 분석하였다. 연구 결과 여아의 유아 또래 상호작용은 교수효능감에 영향을 받고, 남 아의 유아 또래 상호작용은 교사-유아 상호작용에 영향을 받 는다는 것으로 나타났다. 여러 학자들이 유아 성별 차이의 원 인에 대해 사회문화학적 관점에서 부모, 교사, 또래의 영향을 언급한다(Han, 2004; Siegel, 1987). 부모가 자녀의 성별에 따라 다른 모습을 기대하고, 다른 환경을 마련하는 등의 양육태도 를 보이거나 교사가 성 유형화된 놀이를 제공하여서, 혹은 전 통적인 성 역할에 맞는 놀이를 고집하는 또래로 인해 후천적 인 성차가 발생한다고 보았다. 그 외 일부에서는 성차의 첫 번 째 원인으로 생물학적인 요인으로 제시하기도 한다(S. J. Lee, 2004). 아직까지 유아 성별 차이의 정확한 원인은 제시되지 않 지만 여러 선행연구들과 대규모의 대표성 있는 표본을 이용한 본 연구를 통해 교수효능감과 교사-유아 상호작용, 그리고 유 아 또래 상호작용의 관계에서 유아 성별에 따른 차이가 있음 을 검증하였다. 이미 다수의 연구에서 유아 성별에 따른 또래 관계, 사회성, 언어, 인지발달 등의 차이가 있음을 보고하고 있 기에(S. R. Park \& Park, 2010; Shigetomi, Hartmann \& Gelfand, 1981; Zarbatany, Hartmann, Gelfand, \& Vinciguerra, 1985), 본 연구에서 발견된 남아와 여아가 영향을 받는 관계가 다르다는 결과는 추후 그 원인에 대한 연구와 교육현장에서 이를 고려 한 접근법에 대한 새로운 과제일 것이다.

특정성별에 대한 혐오, 성별 갈등이 심화되고 있는 현 시점 에서 잘못된 성 가치관은 자칫 성에 대한 이해나 성 평등이 아 닌 성에 대한 획일적인 시각을 만들어낼 수 있다. 성 가치관과 달리 성별은 어느 쪽이 더 우월하거나 존중받는 것이 아닌 선 천적인 요인이다. 따라서 성별에 따른 차이 그 자체로 인정하 고, 이해한다면 개별 차이를 배려한 상호작용이 가능할 것이 다. 유아는 놀이를 통해 스스로 또래와의 관계를 만들어가기 에(M.-S. Kim \& Suh, 2018), 그 과정에서 고려된 개별성은 상 호작용의 질을 높일 수 있다. 이를 통해 추후 유아교사를 대상 으로 한 연수 및 교육 프로그램 구성시 본 연구결과를 고려할 필요성이 시사된다.

본 연구는 한국아동패널의 자료를 사용했기에 각 변인에 충분한 하위 요인이 포함되어 있는지 고려해 볼 필요성이 있 다. 또한 조절변인으로 유아 성별 한 요소만 고려하였는데 후 속 연구에서는 유아 성별 외에도 본 연구에서 설정한 변인간 
의 관계에 영향을 줄 수 있는 보다 다양한 요인들을 살펴보 는 것이 필요할 것이다. 본 연구에 사용된 교수효능감과 교사유아 상호작용, 유아 또래 상호작용은 모두 교사에 의해 평정 된 데이터라는 한계점이 있다. 하지만 유아의 행동에 대한 인 식은 부모에 비해 교사가 더 평균적이고, 정확하게 인식하고 있기에(Firmin, Proemmel \& Hwang, 2005; Schmitz, Saudino, Plomin, Fulker, \& DeFries, 1996), 데이터의 객관성과 신뢰도가 확보된다. 본 연구의 의의를 살펴보면 다음과 같다. 첫째, 한국 아동패널자료를 이용함으로써 표본이 모집단의 대표성이 일 정 수준 인정된다. 둘째, 기존 연구에서 다루지 않았던 만 3세 유아를 대상으로 아직 상호작용이 정형화되어 있는 않은 유아 의 교수효능감과 교사-유아 상호작용 그리고 유아 또래 상호 작용의 관계를 살펴보았다. 셋째, 유아교사의 교사-유아 상호 작용의 매개를 통해 교수효능감과 유아 또래 상호작용의 관계 를 살펴봄으로써 교사와 유아 그리고 또래의 관계를 심도 있 게 알아보았다. 그리고 이를 통해 유아교육의 질적 향상을 위 한 교사-유아 상호작용의 중요성을 제고시켰다. 마지막으로 교사-유아 상호작용과 교수효능감, 유아 또래 상호작용의 관 계에서 유아의 성별에 따른 차이를 발견하여 유아교육 현장에 서 이를 고려한 교육 프로그램의 구성의 필요성을 마련하였다 는 점에서 의의가 있다.

\section{Notes}

This article was presented at the 2018 Annual Spring Conference of the Korean Association of Child Studies.

\section{Conflict of Interest}

No potential conflict of interest relevant to this article was reported.

\section{References}

\section{In English}

Ashton, P. (1984). Teacher efficacy: A motivational paradigm for effective teacher education. Journal of Teacher Education, 35(5), 28-32. doi:10.1177/002248718403500507
Bagdi. A. \& Vacca. J. (2005). Supporting early childhood socialemotional well being: The building blocks for early learning and school success. Early Childhood Education Journal, 33(3), 145-150. doi:10.1007/s10643-005-0038-y

Baker. J. A. (2006). Contributions of teacher-child relationships to positive school adjustment during elementary school. Journal of School Psychology, 44(3), 211-229. doi:10.1016/ j.jsp.2006.02.002

Brich, S. H., \& Ladd, G. W. (1997). The teacher-child relationship and children's early school adjustment. Journal of School Psychology, 35(1), 61-79. doi:10.1016/s0022-4405(96)00029-5

Eassa, E. S. (2003). Introduction to early childhood education (7th ed.). Clifton Park, NY: Thomson/Delmar Learning.

Firmin, M. W., Proemmel, E., \& Hwang, C. (2005). A comparison of parent and teacher ratings of children's behaviors. Educational Research Quarterly, 29(2), 18-28.

Gibson, S. \& Dembo, M. H. (1984). Teacher efficacy: A Construct validation. Journal of Educational Psychology, 76(4), 559582. doi:10.1037/0022-0663.76.4.569

Hamre, B. K., Pianta, R. C., Downer, J. T., \& Mashburn, A. J (2008). Teacher' perception of conflict with young students: Looking beyond problem behaviors. Social Development, 17(1), 115-136. doi:10.1111/j.1467-9507.2007.00418.x

Hestense, L. L., Kontos, S., \& Bryan, Y. (1993). Children's emotional expression in child care centers varying in quality. Early Childhood Research Quarterly, 8(3), 293-307. doi:10.1016/ s0885-2006(05)80069-9

Howes, C., \& Smith, E. W. (1995). Relations among child care quality, teacher behavior, children's play behaviors, emotional security and cognitive activity in child care. Early Childhood Research Quarterly, 10(4), 381-404. doi:10.1016/0885-2006(95)90013-6

Howes, C. (1997). Teacher sensitivity, children's attachment and play with peer. Early Education and Development, 8(1), 4149. doi:10.1207/s15566935eed0801_4

Ladd, G. W., \& Burgess, K. B. (2001). Do relational risks and protective factors moderate the linkages between childhood aggression and early psychological and school adjustment?. Child Development, 72(5), 1579-1601. doi:10.1111/14678624.00366

Mashburn, A. J., Hamre, B. K., Downer, J. T. \& Pianta, R. C. (2006). Teacher and classroom characteristics associated with teacher's ratings of prekindergarten' relationships and behavior. Journal of Psychoeducational Assessment, 24(4), 367-380. doi:10.1177/0734282906290594

Murray, C., \& Murray, K. M. (2004). Child level correlates of teacher-student relationship: An examination of characteristics, academic orientations, and behavioral orientations. Psychology in the Schools, 41(7), 751-762. doi:10.1002/pits.20015

Organization for Economic Cooperation and Development. (2012). Starting 
Strong III: A quality toolbox for early childhood education and care. OECD Publishing. doi:10.1787/9789264123564-en

Pianta, R. C., \& Steinberg, M. (1992). Teacher-child relationships and the process of adjusting to school. New Directions for Child and Adolescent Development, 57(1), 61-80. doi:10.1002/cd.23219925706

Pianta, R. C. (1994). Patterns of relationships between children and kindergarten teachers. Journal of School Psychology, 32(1), 15-31. doi:10.1016/0022-4405(94)90026-4

Schmitz, S., Saudino, K. J., Plomin, R., Fulker, D. W., \& DeFries, J. C. (1996). Genetic and environmental influences on temperament in middle childhood: Analyses of teacher and tester ratings. Child Development, 67(2), 409-422. doi: $10.2307 / 1131823$

Shigetomi, C. C., Hartmann, D. P., \& Gelfand, D. M. (1981). Sex differences in children's altruistic behavior and reputations for helpfulness. Developmental Psychology, 17(4), 434-437. doi:10.1037//0012-1649.17.4.434

Siegel, M. (1987). Are sons and daughters treated more differently by fathers than by mothers? Developmental Review, 7(3), 183-209. doi:10.1016/0273-2297(87)90012-8

Teltsch, T \& Breznitz, Z. (1988). The effect of school entrance age on academic achievement and social-emotional adjustment of children. The Journal of Genetic Psychology, 149(4), 471483. doi:10.1080/00221325.1988.10532174

Zarbatany, L., Hartmann, D. P., Gelfand, D. M., \& Vinciguerra, P. (1985). Gender differences in altruistic reputation: Are they artifactual? Developmental Psychology, 21(1), 97-101. doi:10.1037//0012-1649.21.1.97

\section{In Korean}

Ann, S. H. (2002). A Study on preschool children's early school adjustment. Journal of Future Early Childhood Education, 9(1), 201-219.

Cheon, H. S., \& Cho, E. J. (2011). An analysis of teacher-child relationships as perceived by teachers and children and the variables affecting such relationships. Korean Journal of Child Studies, 32(4), 167-183. doi:10.5723/kjcs.2011.32.4.167

Chi, S.-A., \& Jung, J.-E. (2011). A study on the relationships among children's emotional intelligence, cognitive ability, children's peer relationships, and child-teacher relationships. Korean Journal of Early Childhood Education, 15(5), 335358.

Choi, H. Y., \& Shin, H. Y. (2011). Validation of the Penn Interactive Peer Play Scale for Korean young children with a special focus on confirmatory factor analysis. Korean Journal of Child Studies, 32(2), 35-52. doi:10.5723/kjcs.2011.32.2.35

Han, M.-N. (2004). The difference of rearing attitude between father and mother influencing on children's problem behavior. The Journal of Child Education, 13(2), 279-291.

Heo, M.-S. (2017). Gender-based violence and hate crime: Is violence against women a form of hate crime?. Journal of Korean Women's Studies, 33(2), 77-105. doi:10.30719/ jkws.2017.06.33.2.77

Kang, B.-J. (2010). The effect of family interaction, children's peer interaction, and social force on the children's problematic behavior. The Journal of Child Education, 19(4), 93-110.

Kim, H. J., \& Cho, B. H. (2009). The study on constructing child care teacher education programs for enhancing infant-teacher interaction and analyzing its effects. Korean Journal of Human Ecology, 18(6), 1221-1235. doi:10.5934/kjhe.2009.18.6.1221

Kim, H. J., \& Jean, K. A. (2010). Influence of child-teacher relationships and children's self-regulation ability on the children's peer interactions. Korean Journal of After-School Child Education, 7(2), 17-34.

Kim, K.-S., \& Kim, Y.-H. (2011). Young children's adjustment in day care centers and reciprocal perceptions between teachers and young children. Early Childhood Education Research \& Review, 15(4), 141-160.

Kim, M. J. (1991). A study on the quality of early education institutions and the degree of job satisfaction of kindergarten teachers (Master's thesis). Retrieved from http://www.riss. $\mathrm{kr} / \mathrm{link}$ ?id=T902025

Kim, M.-S., \& Suh, Y.-S. (2018). The meaning of children's experiences in "real" play. Korean Journal of Early Childhood Education, 38(3), 349-368. doi:10.18023/kjece.2018.38.3.015

Kim, Y.-H., \& Cho, H.-S. (2007). 3 year-old children's emotional needs emerging from their daily life in a kindergarten classroom. Early Childhood Education Research \& Review, 11(1), 181-213.

Kim, Y. H., \& Kim, Y. E (2008). An analysis of the factorial validity of Bandura's teacher self-efficacy scale. Korean Journal of Early Childhood Education, 28(2), 169-191. doi:10.18023/kjece.2008.28.2.008

Kim, Y.-H., \& Park, J.-H. (2014). The relationship between teacher-child interaction and peer play behaviors among young children: The moderating role of parent-teacher partnerships. Korean Journal of Early Childhood Education, 34(3), 135-152.

Kwon, R.-H., \& Lee, J.-H. (2015). The relationship among teacher-child interaction, teachers' beliefs, job satisfaction, and teaching efficacy of kindergarten teachers. The Journal of Child Education, 24(2), 93-107. doi:10.17643/ kjce.2015.24.2.06

Kwon, Y.-H. (2012). The moderating role of teacher-child conflictual relationship on children's negative emotionality and peer interaction. Korean Journal of Early Childhood Education, 32(2), 29-48. doi:10.18023/kjece.2012.32.2.002

Lee, S. J. (2004). Yualeul wihan nol-iui ilongwa silje[유아를 위한 
놀이의 이론과 실제; 제 3판]. Seoul: Changjisa.

Lee, J. H., \& Kim, H. Y. (2012). A study on variables related to positive and negative peer interactions of young children. Journal of Korean Child Care and Education, 8(6), 301-322.

Moon, E.-S., \& Kim, M.-H. (2011). The relationship between mothers' attitudes toward their children's expressiveness, teacher-child relationship and problematic behavior in preschoolers. The Journal of Eco Early Childhood Education o. Care, 10(2), 59-81.

Moon, Y. K., \& Choi, S. N. (2015). Teachers' teaching efficacy on preschoolers' peer interaction: Focusing on the mediating effect of teachers-child interaction. Korean Journal of Child Education and Care, 15(2), 1-20.

Na, D.-S. (2007). The effects of child care teacher's self-efficacy and quality of teacher-child relationship on the social adjustment of children. Korea Journal of Child Care and Education, 48, 19-34.

Paik, Y.-S., \& Kang, B.-J. (2014). The relations a between teacher's emotional labor and teacher-young children interactions in the mediating effects of teaching efficacy and the instructional creativity of day care center teachers. The Journal of Korea Open Association for Early Childhood Education, 19(2), 179-200.

Park, C. H., \& Na, J. (2012). An analysis of teacher-child interaction level based on factors of characteristics of institution, teacher, and child group. Journal of Korean Child Care and Education, 8(6), 99-125.

Park, C. O., \& Kim, E. H. (1995). 3se yualeul wihan 12gaewol gyoyug hwaldong[3세 유아를 위한 12 개월 교육활동]. Seoul: Dongmunsa.

Park, J.-Y., Kang, S.-D., \& Kwon, K.-S. (2010). The effects of age, sex, temperament, income, mother's emotional expressiveness, and mother's social competence on children's peer competence. The Journal of Korea Open Association for Early Childhood Education, 15(5), 359-382.

Park, S. R., \& Park, H. J. (2010). An analysis of the cognitive processes of 5-year-old children: A focus on a performance of cognitive assessment system based on gender, monthly age, and tendencies towards hyperactivity. Korean Journal of Child Studies, 31(4), 139-157.

Park, Y.-A. (2013). Gender differences in the influences of social self-concepts and teacher-child relationships on childcare center adjustment. Korea Journal of Child Care and Education, 76, 1-24.

Shin, H. Y., \& Rhee, U. H. (2005). Effects of teachers' job stress and belief of efficacy on the quality of teachers' interaction behaviors in child care. Korean Journal of Child Studies, 26(5), 105-121.

Sim, S. Y., \& Lim, S. A. (2017). The relationship among teacher efficacy, teacher-child interaction, and peer play interaction: Mediation effect of child temperament. Korean Journal of Early Childhood Education, 37(4), 353-369. doi:10.18023/ kjece.2017.37.4.014

Suh, Y. S., Suh, H. J., Kim, Y. M., Chea, H. S., \& Kim, J. S. (2013). Introduction to child care and education. Paju: Yangseowon.

Suh, Y. S., \& Suh, J. Y. (2005). Job satisfaction of foreign English teachers in Korea and their adjustment to Korean life, and their burnout. Journal of Future Early Childhood Education, 12(1), 123-144. doi:10.24211/tjkte.2014.31.1.293

Yeom, J.-S. (2005). Practice of caring and it's limitation in early childhood classroom. Korean Journal of Early Childhood Education, 25(5), 147-172.

\section{ORCID}

Mi-So Kim http://orcid.org/0000-0002-3697-8305

Young-Sook Suh https://orcid.org/0000-0002-4349-7614

Received June 30, 2018

Revision received July 28, 2018

Accepted August 10, 2018 